\title{
Biomechanical analysis of an expandable lateral cage and a static transforaminal lumbar interbody fusion cage with posterior instrumentation in an in vitro spondylolisthesis model
}

\author{
Matthew Mantell, MD, ${ }^{1}$ Mathew Cyriac, MD, MBA, ${ }^{1}$ Colin M. Haines, MD, ${ }^{1}$ Manasa Gudipally, MS, ${ }^{2}$ \\ and Joseph R. O'Brien, MD, MPH'
} ${ }^{1}$ Department of Orthopaedic Surgery, George Washington University, Washington, DC; and ${ }^{2}$ Globus Medical, Audubon,
Pennsylvania

OBJECTIVE Insufficient biomechanical data exist from comparisons of the stability of expandable lateral cages with that of static transforaminal lumbar interbody fusion (TLIF) cages. The purpose of this biomechanical study was to compare the relative rigidity of $L 4-5$ expandable lateral interbody constructs with or without additive pedicle screw fixation with that of L4-5 static TLIF cages in a novel cadaveric spondylolisthesis model.

METHODS Eight human cadaver spines were used in this study. A spondylolisthesis model was created at the L4-5 level by creating 2 injuries. First, in each cadaver, a nucleotomy from 2 channels through the anterior side was created. Second, the cartilage of the facet joint was burred down to create a gap of $4 \mathrm{~mm}$. Light-emitting-diode tracking markers were placed at L-3, L-4, L-5, and S-1. Specimens were tested in the following scenarios: intact model, bilateral pedicle screws, expandable lateral 18-mm-wide cage (alone, with unilateral pedicle screws [UPSs], and with bilateral pedicle screws [BPSs]), expandable lateral 22-mm-wide cage (alone, with UPSs, and with BPSs), and TLIF (alone, with UPSs, and with BPSs). Four of the spines were tested with the expandable lateral cages (18-mm cage followed by the 22-mm cage), and 4 of the spines were tested with the TLIF construct. All these constructs were tested in flexion-extension, axial rotation, and lateral bending.

RESULTS The TLIF-alone construct was significantly less stable than the 18- and 22-mm-wide lateral lumbar interbody fusion (LLIF) constructs and the TLIF constructs with either UPSs or BPSs. The LLIF constructs alone were significantly less stable than the TLIF construct with BPSs. However, there was no significant difference between the 18-mm LLIF construct with UPSs and the TLIF construct with BPSs in any of the loading modes.

CONCLUSIONS Expandable lateral cages with UPSs provide stability equivalent to that of a TLIF construct with BPSs in a degenerative spondylolisthesis model.

http://thejns.org/doi/abs/10.3171/2015.4.SPINE14636

KEY WORDS lateral lumbar interbody fusion; transforaminal lumbar interbody fusion; pedicle screw; biomechanical

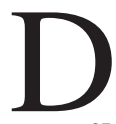
EGENERATIVE lumbar spondylolisthesis is one of many causes of spinal stenosis. Conservative nonsurgical management is the mainstay of treatment. ${ }^{27}$ However, when nonoperative treatment fails, there are a number of different surgical options. Lateral lumbar interbody fusion (LLIF) performed using a transpsoas approach is a minimally invasive technique that can be used to treat patients with degenerative lumbar spondylolisthesis and resulting neuroforaminal stenosis. , $^{1,320,23,30}$

The morbidity rate for minimally invasive LLIF for degenerative scoliosis has been reported to be lower than that for traditional posterior open procedures., ${ }^{2,8,14}$ Studies have shown reduced hospital stay, less blood loss, and decreased narcotic use with LLIF., ${ }^{1,2}$ Fusion rates for both

ABBREVIATIONS BPS = bilateral pedicle screw; $\mathrm{CL} n=n$-mm Caliber-L cage; HSD = Tukey's honest significant difference; LLIF = lateral lumbar interbody fusion; LLIF $n=$ $n$-mm LLIF cage; ROM = range of motion; TLIF = transforaminal lumbar interbody fusion; UPS = unilateral pedicle screw.

SUBMITTED June 25, 2014. ACCEPTED April 10, 2015.

INCLUDE WHEN CITING Published online September 18, 2015; DOI: 10.3171/2015.4.SPINE14636. 
procedures are similar and may be, in some cases, superior with LLIF. Although a lateral approach for degenerative spondylolisthesis may be more technically difficult, it may have an advantage with a decreased morbidity rate for this pathology.

Lateral interbody cages are all indicated for use with supplemental pedicle fixation. Stand-alone lateral interbody constructs can be used, but there have been reports of subsidence with 18- $\mathrm{mm}$ and, to a lesser degree, 22-mm cages. ${ }^{16}$ It is advantageous to use an expandable cage because it provides increasing stability when compared with that of a static cage. ${ }^{12}$ A stand-alone lateral procedure is advantageous because there is no need for separate surgical sites or for repositioning the patient, which increase operative times and cost expenditures. However, failure of a stand-alone lateral construct can lead to continued pain and disability and to reoperation. ${ }^{17,18}$ Posterior pedicle fixation to decrease this risk and further increase the stability of a construct can be added to enhance the strength of the construct and optimize patient treatment while reducing subsequent morbidity. Previous studies have examined both unilateral pedicle screw (UPS) and bilateral pedicle screw (BPS) fixation and found that their effectiveness was similar., ${ }^{9,29}$

The purpose of this study was to examine the relative stability of the expandable lateral construct compared with that of a static transforaminal lumbar interbody fusion (TLIF) cage. To our knowledge, no biomechanical study has been performed to compare lateral expandable cages with or without posterior pedicle screw augmentation with static TLIF cages with or without posterior pedicle screw augmentation.

\section{Methods}

\section{Specimen Preparation and Characteristics}

Lumbosacral motion segments (L3-S1) were dissected from 8 fresh-frozen cadaveric specimens. The average age of the cadavers was 59 years (range 46-70 years). There were 5 male and 3 female cadavers. Dual-energy X-ray absorptiometry (DEXA) scans were not obtained; however, no implant or screw loosening was subsequently noted during the study. Anterior-posterior and lateral radiographs, as well as visual inspection, were used to confirm that the specimens were free of fractures, deformities, and any metastatic diseases. Before actual testing, the spines were dissected by carefully denuding the paravertebral musculature while avoiding disruption of spinal ligaments, joints, and intervertebral discs. The specimens were kept frozen and then thawed to room temperature before use. Specimens were potted, incorporating half of the L-3 vertebral body at the superior end and half of the S-1 vertebral body at the inferior end, with the L3-4 level positioned horizontally.

\section{Test Apparatus}

All the spines were tested sequentially on a custom-built 6-degrees-of-freedom spine simulator. The spine-simulator design, which is based on frictionless air-bearing rails, enables unconstrained motion of the spine in response to an applied load. The S-1 vertebra of each spine was fixed to the load frame of the spine simulator, and a pure moment was applied to the L-3 vertebra through servomotors. Three infrared light-emitting diodes, mounted noncolinearly on a Plexiglas plate, were rigidly attached to the anterior aspect of each vertebral body. The 3D range of motion (ROM) of each segment was tracked by an Optotrak Certus (NDI, Inc.) motion-analysis system. L4-5 ROM was recorded in the form of Euler angles (degrees) from all 3 Cartesian axes for flexion-extension, lateral bending, and axial rotation, respectively.

\section{Test Protocol}

Each construct was tested under 3 loading conditions, flexion-extension, lateral bending, and axial rotation, by using a load-control protocol of $\pm 8 \mathrm{~N} \times \mathrm{m}$ applied at a rate of $1 \%$ second. Eight human cadaver spines (L3-S1) were tested on a 6-degree-of-freedom spine simulator in flexion-extension, lateral bending, and axial rotation with a load of $\pm 8 \mathrm{~N} \times \mathrm{m}$ to measure ROM.

\section{Degenerative Spondylolisthesis Model}

Degenerative spondylolisthesis was simulated by performing a nucleotomy through 2 anterior channels (Fig. 1) and by creating a 4-mm gap in the facet joint at L4-5 (Fig. 2). During the nucleotomy, a significant amount of disc was resected. Furthermore, burring of the facets helped to create further destabilization, resulting in a biomechanical model similar to that proposed by Crawford et al. ${ }^{7}$

\section{Instrumentation of Cadaveric Specimens}

A number of instrumentation methods were investigated at the L4-5 level. Four of the 8 spines were tested with the lateral expandable cage constructs. For the lateral cages, the 18-mm construct ( LLIF $_{18}$, Caliber-L [CL], Globus Medical) was inserted. This stand-alone cage underwent the biomechanical testing described above. UPS and BPS fixation were both tested separately with the lateral $18-\mathrm{mm}$ cage. After testing of these 3 constructs, all hard-

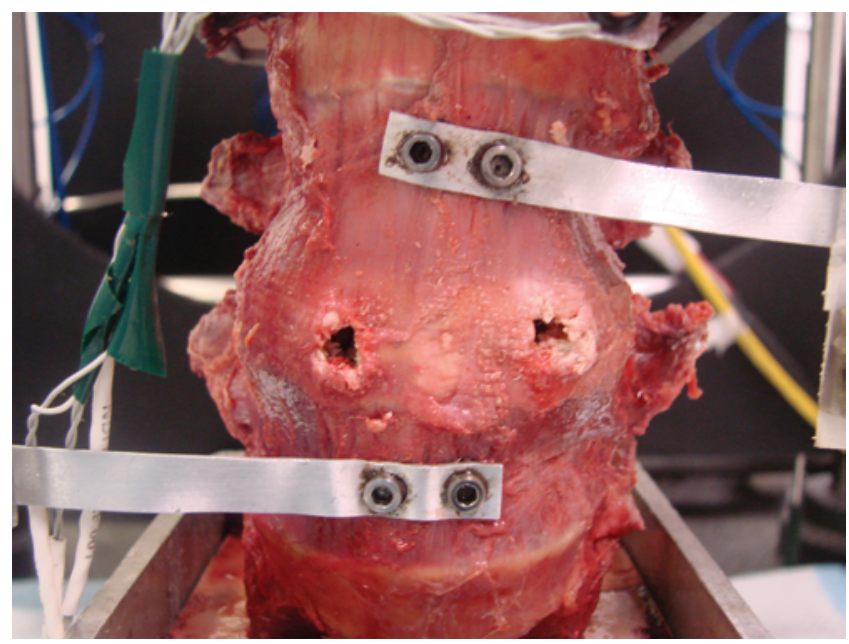

FIG. 1. Nucleotomy and disc resection performed through 2 anterior channels to simulate degenerative spondylolisthesis. Figure is available in color online only. 


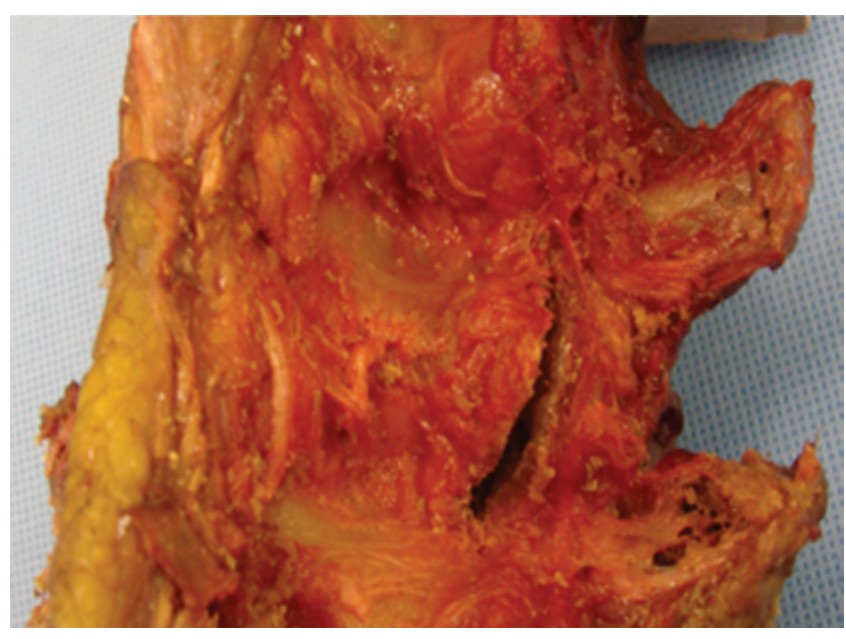

FIG. 2. Four-millimeter gap created in the facet joint at $L 4-5$ to simulate degenerative spondylolisthesis. Figure is available in color online only.

ware was removed, and the 22-mm cage $\left(\mathrm{LLIF}_{22}, \mathrm{CL}\right)$ was inserted after the lateral discectomy was widened slightly to accommodate the larger construct. This construct was again tested alone and with UPS and BPS fixation.

The other 4 spines were tested separately with the static interbody TLIF cage constructs (Sustain O, Globus Medical). A unilateral facetectomy was performed to insert the cage. Biomechanical testing was performed with the stand-alone cage, UPSs, and BPSs. For each spine, we radiographically measured the intact disc height and matched the implant heights to that of the intact condition. All of the instrumentations were performed by the senior author (J.R.O.) and were noted to be equally snug. The sizing of the TLIF cage ranged from 8 to $10 \mathrm{~mm}$ in width, 9 to $12 \mathrm{~mm}$ in height, and 26 to $30 \mathrm{~mm}$ in length based on specific cadaveric anatomy.

The test sequence was as follows: 1) intact, 2) BPSs, 3) spondylolisthesis model, 4) $\mathrm{LLIF}_{18}$ alone, 5) $\mathrm{LLIF}_{18}$ plus UPSs, 6) $\mathrm{LLIF}_{18}$ plus BPSs, 7) $\mathrm{LLIF}_{22}$ alone, 8) $\mathrm{LLIF}_{22}$ plus UPSs, 9) LLIF $_{22}$ plus BPSs, 10) TLIF cage alone, 11) TLIF cage plus UPSs, and 12) TLIF cage plus BPSs.

The pedicle screws used were $6.5 \mathrm{~mm}$ in diameter and $45 \mathrm{~mm}$ in length and were the same for both the LLIF and TLIF constructs. In half (4 of 8) of the spines, the LLIF constructs were tested after creating the injury, followed by the TLIF constructs, and for the remaining 4 spines, the TLIF constructs were tested after creating the injury, followed by the LLIF constructs.

Randomization was performed between the lateral interbody cages and the TLIF construct to test after the spondylolisthesis model construct. Two preload cycles were applied before each loading condition to minimize the viscoelastic response of the spine. Data were collected during the third loading cycle. During testing, the models were moistened with $0.9 \%$ sodium chloride irrigation.

In all cases, to alleviate the homogeneity of variance, $\log$ transforms in the form of $\log _{10}$ (raw data +1 ) were applied to the raw data, and then repeated-measures ANOVA was performed for significance ( $\mathrm{p}<0.05)$. After completing the ANOVA, Tukey's honest significant difference
(HSD) post hoc test was used to determine which groups in the sample differed from each other. Data achieved statistical significance if the difference in the means of the 2 study groups was greater than or equal to the HSD value generated by the post hoc test.

\section{Results}

The ROM for each construct is shown in Fig. 3, and the ROMs for all 12 models in flexion-extension, lateral bending, and axial rotation are shown as well (Fig. 3).

Data and their significance are listed in Tables 1-3.

\section{Flexion-Extension}

When tested, all the constructs resulted in significantly decreased ROM compared with that of the intact and spondylolisthesis models except for the stand-alone TLIF cage. There was no significant difference found between the $\mathrm{LLIF}_{18}+\mathrm{BPSs}, \mathrm{LLIF}_{22}$, and TLIF+BPSs groups. There was no significant difference between the LLIF $_{18}$ and stand-alone $\mathrm{LLIF}_{22}$. The stand-alone TLIF construct was significantly less stable than all the $\mathrm{LLIF}_{18}$ constructs, and all LLIF $_{22} \mathrm{~s}$, TLIF+UPSs, and TLIF+BPSs. Both the $\mathrm{LLIF}_{18}$ and the $\mathrm{LLIF}_{22}$ alone were less stable than the TLIF+BPS construct.

\section{Lateral Bending}

All of the test constructs significantly reduced ROM over that with the intact model except for TLIF+UPSs. All of the test constructs significantly reduced ROM over that of the spondylolisthesis model injury except for the TLIF construct alone. There was no significant difference between BPSs and $\mathrm{LLIF}_{18}, \mathrm{LLIF}_{22}$, and TLIF+BPSs. There was no significant difference between stand-alone LLIF $_{18}$ and LLIF $_{22}$. The TLIF cage alone was significantly less stable than all $\mathrm{CL}_{18}$ and $\mathrm{CL}_{22}$ constructs and less stable than TLIF+UPSs and TLIF+BPSs. There was not a significant difference between the $\mathrm{LLIF}_{18}, \mathrm{LLIF}_{22}$, and TLIF+BPSs.

\section{Axial Rotation}

All of the test constructs significantly reduced ROM over that of the intact model except for $\mathrm{CL}_{18}+\mathrm{UPSs}$, $\mathrm{CL}_{22}+\mathrm{UPSs}$, and TLIF+BPSs. All of the test constructs significantly reduced ROM over that of the spondylolisthesis model except for the stand-alone $\mathrm{LLIF}_{18}$ and stand-alone TLIF cage. There was no significant difference between BPSs and $\mathrm{LLIF}_{18}+\mathrm{BPSs}, \mathrm{LLIF}_{22}+\mathrm{BPSs}$, or TLIF+BPSs. There was no significant difference between the standalone LLIF $_{18}$ and LLIF $_{22}$. The stand-alone TLIF was significantly less stable than all the $\operatorname{LLIF}_{18} \mathrm{~s}$, all $\mathrm{LLIF}_{22} \mathrm{~s}$, and the TLIF+UPSs and TLIF+BPSs. The stand-alone LLIF and LLIF $_{22}$ were significantly less stable than TLIF+BPSs.

\section{Discussion}

In this experimental model, we recreated a Grade I spondylolisthesis with 2 injuries: a 4-mm facet joint burring and a nucleotomy. Restabilization of the experimentally created listhesis was performed with 1) posterior pedicle instrumentation, 2) LLIF with and without instru- 


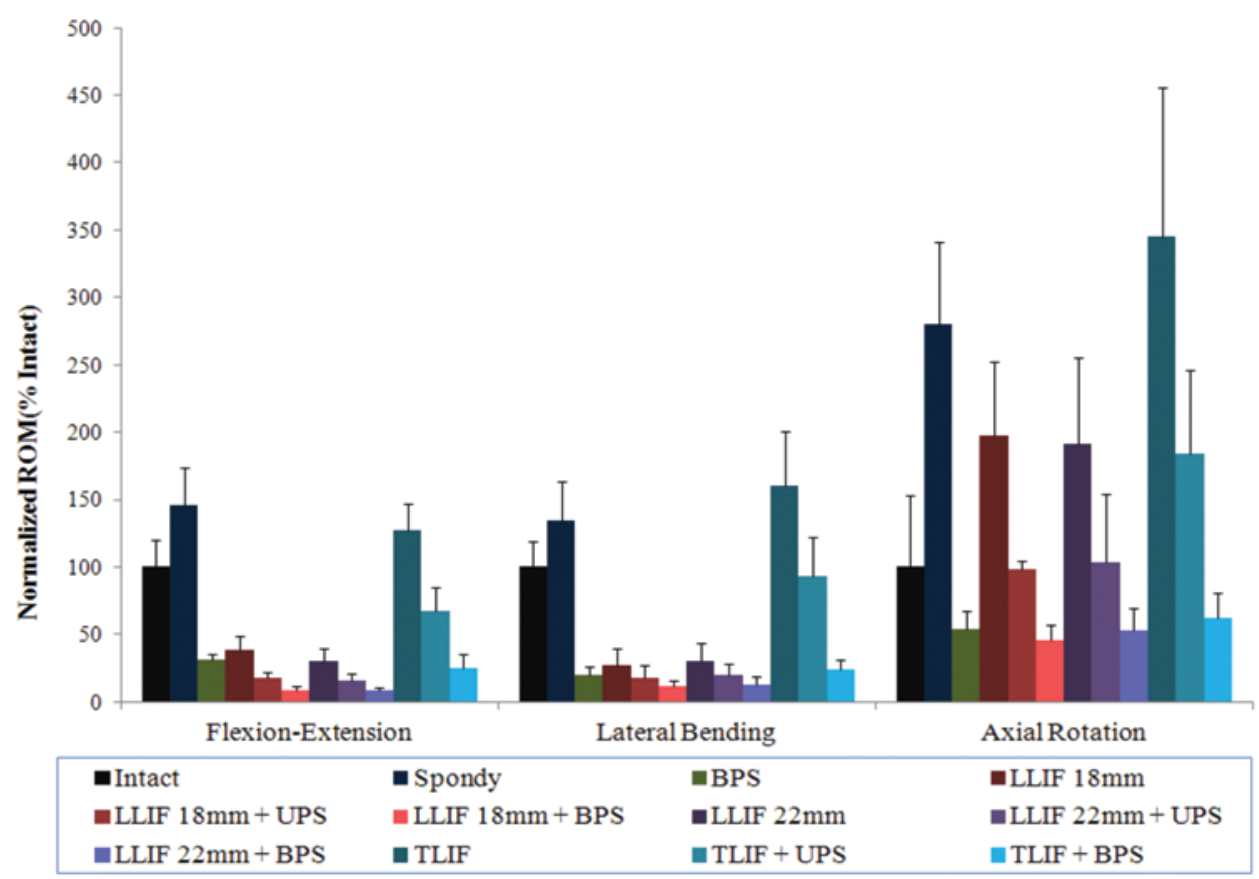

FIG. 3. Range of motion for each construct. Each construct was tested in flexion-extension, lateral bending, and axial rotation. Spondy = spondylolisthesis model; LLIF 18mm = 18-mm LLIF cage; LLIF 22mm = 22-mm LLIF cage. Figure is available in color online only.

mentation, and 3) TLIF with and without instrumentation. Comparisons were made between these modes of treatment of a Meyerding Grade I spondylolisthesis.

Lateral interbody fusion has gained acceptance in many medical centers for the treatment of spondylolisthesis, stenosis, scoliosis, tumors, and trauma. ${ }^{3,8,20}$ Generally, decompression of the neural elements is achieved by realignment of the spine and distraction of the vertebral bodies to restore neuroforaminal height and open the central zone. Reports have shown up to a 54\% increase in the anterior-to-posterior plane and a $48 \%$ increase in the medial-lateral plane after LLIF. ${ }^{11}$ Kepler et al. ${ }^{15}$ showed an average foraminal increase of $35 \%$ after lateral cage placement.

Good clinical outcome after LLIF partially depends on the avoidance of subsidence. A number of studies have examined the relative stability of $18-\mathrm{mm}$ and $22-\mathrm{mm}$ cages for LLIF, ${ }^{16}$ and although stand-alone LLIF is off-label use, many surgeons do perform LLIF without supplemental fixation and encounter good results. Supplemental fixation

TABLE 1. Tukey's HSD post hoc analysis for all the study groups in flexion-extension*

\begin{tabular}{|c|c|c|c|c|c|c|c|c|c|c|c|}
\hline Flex-Ex & Intact & Spondy & BPSs & $\mathrm{LLIF}_{18}$ & $\begin{aligned} & \text { LLIF }_{18} \\
& \text { +UPSS }\end{aligned}$ & $\begin{array}{l}\text { LLIF }_{18} \\
\text { +BPSS }\end{array}$ & LLIF $_{22}$ & $\begin{array}{l}\text { LLIF }_{22} \\
\text { +UPSs }\end{array}$ & $\begin{array}{l}\text { LLIF }_{22} \\
\text { +BPSs }\end{array}$ & TLIF & $\begin{aligned} & \text { TLIF } \\
+ & \text { UPSS }\end{aligned}$ \\
\hline Spondy & $0.15 \dagger$ & & & & & & & & & & \\
\hline BPSs & $0.42 \dagger$ & $0.57 \dagger$ & & & & & & & & & \\
\hline LLIF $_{18}$ & $0.35 \dagger$ & $0.50 \dagger$ & 0.07 & & & & & & & & \\
\hline LLIF $_{18}+$ UPSs & $0.59 \dagger$ & $0.74 \dagger$ & $0.17 \dagger$ & $0.24 \dagger$ & & & & & & & \\
\hline LLIF $_{18}+$ BPSs & $0.75 \dagger$ & $0.90 \dagger$ & $0.33 \dagger$ & $0.40 \dagger$ & $0.16 \dagger$ & & & & & & \\
\hline LLIF $_{22}$ & $0.44 \dagger$ & $0.59 \dagger$ & 0.02 & 0.09 & $0.15 \dagger$ & $0.30 \dagger$ & & & & & \\
\hline LLIF $_{22}+$ UPSs & $0.63 \dagger$ & $0.78 \dagger$ & $0.21 \dagger$ & $0.28 \dagger$ & 0.04 & 0.11 & $0.19 \dagger$ & & & & \\
\hline LLIF $_{22}+$ BPSs & $0.76 \dagger$ & $0.91 \dagger$ & $0.34 \dagger$ & $0.41 \dagger$ & $0.18 \dagger$ & 0.02 & $0.13 \dagger$ & $0.13 \dagger$ & & & \\
\hline TLIF & 0.10 & 0.05 & $0.52 \dagger$ & $0.45 \dagger$ & $0.69 \dagger$ & $0.85 \dagger$ & $0.86 \dagger$ & $0.73 \dagger$ & $0.86 \dagger$ & & \\
\hline TLIF+UPSs & $0.16 \dagger$ & $0.31 \dagger$ & $0.26 \dagger$ & $0.19 \dagger$ & $0.43 \dagger$ & $0.59 \dagger$ & $0.26 \dagger$ & $0.48 \dagger$ & $0.61 \dagger$ & $0.26 \dagger$ & \\
\hline TLIF+BPSs & $0.51 \dagger$ & $0.66 \dagger$ & 0.09 & $0.16 \dagger$ & 0.08 & $0.24 \dagger$ & $0.35 \dagger$ & 0.12 & $0.26 \dagger$ & $0.35 \dagger$ & $0.35 \dagger$ \\
\hline
\end{tabular}

Flex-Ex = flexion-extension; Spondy $=$ spondylolisthesis model.

* The HSD in flexion-extension was 0.13 . If the difference in the mean value of the 2 constructs (row and column) is greater than or equal to the HSD value, then it is statistically significant.

† Significant at a $p<0.05$, as the difference in the means of 2 study groups is greater than or equal to the HSD value. 
TABLE 2. Tukey's HSD post hoc analysis for all the study groups in lateral bending*

\begin{tabular}{|c|c|c|c|c|c|c|c|c|c|c|c|}
\hline LB & Intact & Spondy & BPSs & LLIF $_{18}$ & $\begin{array}{l}\text { LLIF }_{18} \\
+ \text { +UPSs }\end{array}$ & $\begin{array}{l}\text { LLIF }_{18} \\
\text { +BPSs }\end{array}$ & $\mathrm{LLIF}_{22}$ & $\begin{array}{l}\text { LLIF }_{22} \\
+ \text { +UPSs }\end{array}$ & $\begin{array}{l}\text { LLIF }_{22} \\
\text { +BPSs }\end{array}$ & TLIF & $\begin{aligned} & \text { TLIF } \\
+ & \text { UPSS }\end{aligned}$ \\
\hline Spondy & $0.12 \dagger$ & & & & & & & & & & \\
\hline BPSs & $0.53 \dagger$ & $0.65 \dagger$ & & & & & & & & & \\
\hline LLIF $_{18}$ & $0.46 \dagger$ & $0.58 \dagger$ & 0.07 & & & & & & & & \\
\hline LLIF $_{18}+$ UPSs & $0.57 \dagger$ & $0.69 \dagger$ & 0.04 & 0.11 & & & & & & & \\
\hline LLIF $_{18}+$ BPSs & $0.67 \dagger$ & $0.79 \dagger$ & $0.14 \dagger$ & $0.21 \dagger$ & 0.10 & & & & & & \\
\hline LLIF $_{22}$ & $0.43 \dagger$ & $0.55 \dagger$ & 0.10 & 0.03 & $0.14 \dagger$ & $0.24 \dagger$ & & & & & \\
\hline LLIF $_{22}+$ UPSs & $0.54 \dagger$ & $0.66 \dagger$ & 0.01 & 0.08 & 0.03 & $0.13 \dagger$ & 0.11 & & & & \\
\hline LLIF $_{22}+$ BPSs & $0.65 \dagger$ & $0.76 \dagger$ & 0.11 & $0.18 \dagger$ & 0.08 & 0.02 & $0.21 \dagger$ & 0.10 & & & \\
\hline TLIF & $0.18 \dagger$ & 0.07 & $0.72 \dagger$ & $0.64 \dagger$ & $0.75 \dagger$ & $0.85 \dagger$ & $0.61 \dagger$ & $0.72 \dagger$ & $0.83 \dagger$ & & \\
\hline TLIF+UPSs & 0.03 & $0.15 \dagger$ & $0.50 \dagger$ & $0.43 \dagger$ & $0.54 \dagger$ & $0.64 \dagger$ & $0.40 \dagger$ & $0.51 \dagger$ & $0.61 \dagger$ & $0.21 \dagger$ & \\
\hline TLIF+BPSs & $0.49 \dagger$ & $0.61 \dagger$ & 0.04 & 0.03 & 0.08 & $0.18 \dagger$ & 0.06 & 0.05 & $0.15 \dagger$ & $0.67 \dagger$ & $0.46 \dagger$ \\
\hline
\end{tabular}

$\mathrm{LB}=$ lateral bending.

* The HSD in lateral bending was 0.12. If the difference in the mean value of the 2 constructs (row and column) is greater than or equal to the HSD value, then it is statistically significant.

$\dagger$ Significant at a $p<0.05$, as the difference in the means of 2 study groups is greater than or equal to the HSD value.

is an important consideration for preventing fracture and subsidence. ${ }^{25}$

Supplemental fixation may include open or percutaneous pedicle fixation. Pedicle screws offer 3-column fixation. TLIF has been performed with success for degenerative spondylolisthesis. ${ }^{21}$ Both BPS and UPS fixation methods have been used with TLIF cages for degenerative conditions. ${ }^{24}$ There are a number of studies that demonstrated the efficacy of both methods, and some studies showed biomechanical inferiority of TLIF cages with UPSs to TLIF cages with BPSs..$^{22,24}$ More recent studies and a meta-analysis showed no difference in functional outcomes between TLIF cages with BPSs and TLIF cages with UPSs. ${ }^{9,26,29}$ The results of our study, similar to previous biomechanical studies, show that a TLIF cage without posterior supplemental fixation is significantly less stable than a TLIF cage with UPSs or BPSs. ${ }^{13,19}$ Our study reinforces the idea that stand-alone TLIF cages may not provide adequate segmental stability in degenerative spondylolisthesis.

Regardless of unilateral or bilateral fixation, all TLIF surgeries are done with a facetectomy. LLIF does not require a facetectomy or laminectomy and therefore may provide more inherent stability. Previous biomechanical studies have shown that lateral interbody implants may provide the greatest reduction in ROM and that with additive bilateral pedicle fixation, the reduction in ROM is similar to that with other interbody techniques. ${ }^{4,6}$ In this setting, we found that LLIF cages with UPSs afforded the same stability as a TLIF construct with bilateral screws.

TABLE 3. Tukey's HSD post hoc analysis for all the study groups in axial rotation*

\begin{tabular}{|c|c|c|c|c|c|c|c|c|c|c|c|}
\hline AR & Intact & Spondy & BPSs & LLIF $_{18}$ & $\begin{array}{l}\text { LLIF }_{18} \\
+ \text { UPSS }\end{array}$ & $\begin{array}{r}\text { LLIF }_{18} \\
\text { +BPSs }\end{array}$ & $\mathrm{LLIF}_{22}$ & $\begin{array}{l}\text { LLIF }_{22} \\
\text { +UPSs } \\
\end{array}$ & $\begin{array}{l}\text { LLIF }_{22} \\
\text { +BPSs } \\
\end{array}$ & TLIF & $\begin{aligned} & \text { TLIF } \\
&++ \text { UPSS } \\
&\end{aligned}$ \\
\hline Spondy & $0.41 \dagger$ & & & & & & & & & & \\
\hline BPSs & $0.17 \dagger$ & $0.58 \dagger$ & & & & & & & & & \\
\hline LLIF $_{18}$ & $0.27 \dagger$ & 0.14 & $0.44 \dagger$ & & & & & & & & \\
\hline LLIF $_{18}+$ UPSs & 0.01 & $0.40 \dagger$ & $0.18 \dagger$ & $0.26 \dagger$ & & & & & & & \\
\hline $\mathrm{LLIF}_{18}+\mathrm{BPSs}$ & $0.22 \dagger$ & $0.63 \dagger$ & 0.05 & $0.49 \dagger$ & $0.23 \dagger$ & & & & & & \\
\hline $\mathrm{LLIF}_{22}$ & $0.26 \dagger$ & $0.16 \dagger$ & $0.42 \dagger$ & 0.02 & $0.25 \dagger$ & $0.47 \dagger$ & & & & & \\
\hline LLIF $_{22}+$ UPSs & 0.02 & $0.39 \dagger$ & $0.19 \dagger$ & $0.25 \dagger$ & 0.01 & $0.24 \dagger$ & $0.23 \dagger$ & & & & \\
\hline $\mathrm{LLIF}_{22}+\mathrm{BPSs}$ & $0.17 \dagger$ & $0.58 \dagger$ & 0.01 & $0.44 \dagger$ & $0.18 \dagger$ & 0.04 & $0.43 \dagger$ & $0.19 \dagger$ & & & \\
\hline TLIF & $0.48 \dagger$ & 0.07 & $0.65 \dagger$ & $0.21 \dagger$ & $0.47 \dagger$ & $0.70 \dagger$ & $0.23 \dagger$ & $0.46 \dagger$ & $0.66 \dagger$ & & \\
\hline TLIF+UPSs & $0.24 \dagger$ & $0.17 \dagger$ & $0.40 \dagger$ & 0.04 & $0.23 \dagger$ & $0.45 \dagger$ & 0.02 & $0.22 \dagger$ & $0.41 \dagger$ & $0.25 \dagger$ & \\
\hline TLIF+BPSs & 0.13 & $0.54 \dagger$ & 0.04 & $0.40 \dagger$ & 0.14 & 0.09 & $0.38 \dagger$ & $0.15 \dagger$ & 0.05 & $0.61 \dagger$ & $0.36 \dagger$ \\
\hline
\end{tabular}

$\mathrm{AR}=$ axial rotation .

* The HSD in axial rotation was 0.15 . If the difference in the mean value of the 2 constructs (row and column) is greater than or equal to the HSD value, then it is statistically significant.

$\dagger$ Significant at a $p<0.05$, as the difference in the means of 2 study groups is greater than or equal to the HSD value. 
The clinical significance of this finding pertains to ease of operation. Placing a UPS on the side that is up when the patient is in the lateral position is generally more easily done than placing BPSs while in the lateral position. By performing an LLIF with UPS fixation, the surgeon can avoid flipping the patient prone, which reduces operating time and morbidity.

It is important to recognize the limitations of this study, which are similar to those of other biomechanical studies. First, the sample size was small, and there may have been variable bone mineral densities and preexisting intervertebral motion differences. Although the sample size was small, it is still in accordance with the minimum number of specimens required to delineate the differences between various instrumented constructs. ${ }^{28}$ Creating a spondylolisthesis model by performing a nucleotomy and burring the facets may have not accurately recreated true disease pathologies; however, it has been done in previous biomechanical studies. ${ }^{7}$ Second, the testing method enabled us to study immediate stability only and did not take into account additional biological changes that occur in vivo. Osteoporosis may limit the applicability of these results, because a fracture may occur in the vertebral body after LLIF. ${ }^{10}$ There have also been reports indicating that fracture may occur even without osteoporosis. ${ }^{5}$ Furthermore, we did not perform pretesting dual-energy $\mathrm{X}$-ray absorptiometry scans on the cadavers; however, this model was created to determine biomechanical stability, not to perform catastrophic or fatigue testing. In addition, rotational control is generally better with BPS fixation and has yet to be studied in clinical long-term studies. Finally, the fatigue behavior of UPS fixation was not characterized in this study and would need to be characterized in additional biomechanical studies. Some patients may not be able to undergo a lateral procedure at L4-5 secondary to anatomical issues; however, this level was chosen for the study because it is the most frequently affected level in degenerative spondylolisthesis. In addition, this study was performed in a cadaveric model, and application in the clinical setting may not be valid.

Another potential limitation is that the constructs tested may not be equivalent, because an expandable cage was used in the LLIF construct and a static cage was used in the TLIF construct. A recent biomechanical study in which expandable and static lateral interbody cages were compared found that both constructs provide similar immediate stability to a single spine segment. The study concluded that although an expandable cage may be an attractive option for less tissue disruption during implantation, it resulted in higher endplate collapse as a result of overdistraction of the disc space after insertion. The most stable construct was the static lateral interbody cage with BPSs. ${ }^{12}$

\section{Conclusions}

In a degenerative spondylolisthesis model, expandable lateral cages with UPSs provide stability equivalent to that of a TLIF construct with BPSs.

\section{Acknowledgments}

Globus Medical provided the use of its biomechanical testing laboratory and provided cadaveric specimens and implants. Globus Medical also provided statistical assistance, and Manasa Gudipally provided critical review of the manuscript.

\section{References}

1. Ahmadian A, Verma S, Mundis GM Jr, Oskouian RJ Jr, Smith DA, Uribe JS: Minimally invasive lateral retroperitoneal transpsoas interbody fusion for L4-5 spondylolisthesis: clinical outcomes. J Neurosurg Spine 19:314-320, 2013

2. Barbagallo GM, Albanese V, Raich AL, Dettori JR, Sherry N, Balsano M: Lumbar Lateral Interbody Fusion (LLIF): Comparative Effectiveness and Safety versus PLIF/TLIF and Predictive Factors Affecting LLIF Outcome. Evid Based Spine Care J 5:28-37, 2014

3. Basho R, Chen JH: Lateral interbody fusion: indications and techniques. Oper Tech Orthop 24:204-207, 2011

4. Bess RS, Cornwall GB, Vance RE, Bachus N, Brodke DS: Biomechanics of Lateral Arthrodesis, in Goodrich A and Volcan IJ (eds): Extreme Lateral Interbody Fusion (XLIF). St. Louis: Quality Medical Publishing, 2008, pp $31-40$

5. Brier-Jones JE, Palmer DK, Inceoğlu S, Cheng WK: Vertebral body fractures after transpsoas interbody fusion procedures. Spine J 11:1068-1072, 2011

6. Cappuccino A, Cornwall GB, Turner AW, Fogel GR, Duong HT, Kim KD, et al: Biomechanical analysis and review of lateral lumbar fusion constructs. Spine (Phila Pa 1976) 35 (26 Suppl):S361-S367, 2010

7. Crawford NR, Cagli S, Sonntag VK, Dickman CA: Biomechanics of grade I degenerative lumbar spondylolisthesis. Part 1: in vitro model. J Neurosurg 94 (1 Suppl):45-50, 2001

8. Dakwar E, Cardona RF, Smith DA, Uribe JS: Early outcomes and safety of the minimally invasive, lateral retroperitoneal transpsoas approach for adult degenerative scoliosis. Neurosurg Focus 28(3):E8, 2010

9. Deutsch H, Musacchio MJ Jr: Minimally invasive transforaminal lumbar interbody fusion with unilateral pedicle screw fixation. Neurosurg Focus 20(3):E10, 2006

10. Dua K, Kepler CK, Huang RC, Marchenko A: Vertebral body fracture after anterolateral instrumentation and interbody fusion in two osteoporotic patients. Spine J 10:e11-e15, 2010

11. Elowitz EH, Yanni DS, Chwajol M, Starke RM, Perin NI: Evaluation of indirect decompression of the lumbar spinal canal following minimally invasive lateral transpsoas interbody fusion: radiographic and outcome analysis. Minim Invasive Neurosurg 54:201-206, 2011

12. Gonzalez-Blohm SA, Doulgeris JJ, Aghayev K, Lee WE 3rd, Laun J, Vrionis FD: In vitro evaluation of a lateral expandable cage and its comparison with a static device for lumbar interbody fusion: a biomechanical investigation. J Neurosurg Spine 20:387-395, 2014

13. Høy K, Bünger C, Niederman B, Helmig P, Hansen ES, Li H, et al: Transforaminal lumbar interbody fusion (TLIF) versus posterolateral instrumented fusion (PLF) in degenerative lumbar disorders: a randomized clinical trial with 2-year follow-up. Eur Spine J 22:2022-2029, 2013

14. Isaacs RE, Hyde J, Goodrich JA, Rodgers WB, Phillips FM: A prospective, nonrandomized, multicenter evaluation of extreme lateral interbody fusion for the treatment of adult degenerative scoliosis: perioperative outcomes and complications. Spine (Phila Pa 1976) 35 (26 Suppl):S322-S330, 2010

15. Kepler CK, Sharma AK, Huang RC, Meredith DS, Girardi FP, Cammisa FP Jr, et al: Indirect foraminal decompression after lateral transpsoas interbody fusion. J Neurosurg Spine 16:329-333, 2012

16. Marchi L, Abdala N, Oliveira L, Amaral R, Coutinho E, Pimenta L: Radiographic and clinical evaluation of cage 
subsidence after stand-alone lateral interbody fusion. J Neurosurg Spine 19:110-118, 2013

17. Moller DJ, Slimack NP, Acosta FL Jr, Koski TR, Fessler RG, Liu JC: Minimally invasive lateral lumbar interbody fusion and transpsoas approach-related morbidity. Neurosurg Focus 31(4):E4, 2011

18. Nemani VM, Aichmair A, Taher F, Lebl DR, Hughes AP, Sama AA, et al: Rate of revision surgery after stand-alone lateral lumbar interbody fusion for lumbar spinal stenosis. Spine (Phila Pa 1976) 39:E326-E331, 2014

19. Oxland TR, Lund T: Biomechanics of stand-alone cages and cages in combination with posterior fixation: a literature review. Eur Spine J 9 (Suppl 1):S95-S101, 2000

20. Ozgur BM, Aryan HE, Pimenta L, Taylor WR: Extreme Lateral Interbody Fusion (XLIF): a novel surgical technique for anterior lumbar interbody fusion. Spine J 6:435-443, 2006

21. Rosenberg WS, Mummaneni PV: Transforaminal lumbar interbody fusion: technique, complications, and early results. Neurosurgery 48:569-575, 2001

22. Schleicher P, Beth P, Ottenbacher A, Pflugmacher R, Scholz M, Schnake KJ, et al: Biomechanical evaluation of different asymmetrical posterior stabilization methods for minimally invasive transforaminal lumbar interbody fusion. J Neurosurg Spine 9:363-371, 2008

23. Sharma AK, Kepler CK, Girardi FP, Cammisa FP, Huang RC, Sama AA: Lateral lumbar interbody fusion: clinical and radiographic outcomes at 1 year: a preliminary report. J Spinal Disord Tech 24:242-250, 2011

24. Slucky AV, Brodke DS, Bachus KN, Droge JA, Braun JT: Less invasive posterior fixation method following transforaminal lumbar interbody fusion: a biomechanical analysis. Spine J 6:78-85, 2006

25. Sofianos DA, Briseño MR, Abrams J, Patel AA: Complications of the lateral transpsoas approach for lumbar interbody arthrodesis: a case series and literature review. Clin Orthop Relat Res 470:1621-1632, 2012

26. Wang L, Wang Y, Li Z, Yu B, Li Y: Unilateral versus bilateral pedicle screw fixation of minimally invasive transforaminal lumbar interbody fusion (MIS-TLIF): a meta-analysis of randomized controlled trials. BMC Surg 14:87-101, 2014

27. Weinstein JN, Lurie JD, Tosteson TD, Hanscom B, Tosteson
AN, Blood EA, et al: Surgical versus nonsurgical treatment for lumbar degenerative spondylolisthesis. N Engl J Med 356:2257-2270, 2007

28. Wilke HJ, Wenger K, Claes L: Testing criteria for spinal implants: recommendations for the standardization of in vitro stability testing of spinal implants. Eur Spine J 7:148-154, 1998

29. Xue H, Tu Y, Cai M: Comparison of unilateral versus bilateral instrumented transforaminal lumbar interbody fusion in degenerative lumbar diseases. Spine J 12:209-215, 2012

30. Youssef JA, McAfee PC, Patty CA, Raley E, DeBauche S, Shucosky E, et al: Minimally invasive surgery: lateral approach interbody fusion: results and review. Spine (Phila Pa 1976) 35 (26 Suppl):S302-S311, 2010

\section{Disclosure}

Dr. O'Brien is a consultant for Globus Medical and Relivant. He did not receive any funds related to this study. He receives royalties from Globus Medical and NuVasive and has ownership in Spinicity/ISD. Dr. O'Brien does not receive any royalties related to any of the devices tested in this study. He has no intellectual property related to any of the devices in this study or any patents related to any of the devices in this study. Ms. Gudipally is an employee of Globus Medical.

\section{Author Contributions}

Conception and design: O'Brien, Mantell, Cyriac. Acquisition of data: O'Brien, Mantell, Gudipally. Analysis and interpretation of data: O'Brien, Mantell, Cyriac. Drafting the article: O'Brien, Mantell, Cyriac. Critically revising the article: O'Brien, Mantell, Cyriac, Haines. Reviewed submitted version of manuscript: O'Brien, Mantell, Cyriac, Haines. Statistical analysis: Gudipally. Study supervision: O'Brien.

\section{Correspondence}

Joseph R. O'Brien, Department of Orthopaedic Surgery, George Washington University, 2150 Pennsylvania Ave. NW, Washington, DC 20037. email: jobrien@mfa.gwu.edu. 